\title{
NOS Hydrographic Survey Bottom Sample Recovery
}

\author{
Daniel Neumann \\ National Oceanic and Atmospheric Administration \\ 1315 East-West Highway, Station 6739 \\ Silver Spring, Maryland 20910 USA \\ dan.neumann@noaa.gov 301-713-2698 Ext.108
}

\begin{abstract}
The National Oceanic and Atmospheric Administration (NOAA) National Ocean Service (NOS) Hydrographic Survey Division (HSD) and National Geophysical Data Center (NGDC) recently completed a joint project to provide web access to hydrographic survey metadata from the NOS Hydrographic Survey Metadata Database (HSMDB). The new online metadata display is offered on the NGDC web site (http://www.ngdc.noaa.gov/mgg/bathymetry/hydro.html) under the product name Rap Sheet. One innovative feature of this view is a link to the growing database of seabed "bottom type" derived from samples collected during surveys. These samples provide seabed type annotations for nautical charts, but also have applications outside the navigation community.
\end{abstract}

Bottom samples must have a source with adequate geographic location and description. This paper examines the four sources of HSMDB bottom samples: Oceanographic Log "M" Sheets, Descriptive Report tabular listing, digital feature files in CARIS .hob format, and survey Detached Position plots. Preliminary results of the author's ongoing review suggest that adequate bottom type information exists for only seventy percent of the 8,400 surveys with verified metadata in HSMDB (H08000, c.1952, to the present).

This paper will discuss efforts to address the remaining thirty percent of surveys for which there is currently incomplete and/or conflicting bottom sample information in the database. Specifically the discussion will focus on: 1) Auditing the current post-H08000 HSMDB bottom sample holdings, 2) Finding "M" log sheets or survey tabular lists for uncorroborated data and resolving NGDC cruise and HSMDB display conflict, 3) Extracting bottom sample metadata from modern survey digital feature files in CARIS .hob format, and 4) completing all HSMDB Rap Sheet bottom samples with matching NGDC display and NOS count from the best available source

\section{INTRODUCTION}

The following discussion of bottom sample methodology, tools and audit is important because it addresses these problems in the over 58,000 distinct bottom characteristic descriptions encoded in the Hydrographic Survey Meta Data Base (HSMDB) from hydrographic surveys. Collectively they form one of the longest running and most densely spaced records of sediment composition in the coastal waters of the United States. The ongoing audit has verified thousands of additional bottom types and prepped hundreds for conversion to digital form for use in mapping and modeling support of benthic habitat, and pollution, sediment transportation studies and coastal zone management. The scope of this audit is the complete and accurate bottom sample portrayal of the verified portion of the HSMDB. The objective is to complete the geographic position, type display and bottom sample counts for these verified surveys from the best available source. The motivation to do this work comes from the current inability to satisfy all user requests for bottom sample data. Moreover, bottom sample displays for many of the new Rap Sheets is incomplete or in error.

\section{BACKGROUND}

Ocean floor bottom sample grabbing has been around for centuries. Many talks given at the NOAA Library in Silver Spring Maryland refer to a French map dating to 1625 as one of the first maps with bottom type characteristics. The first use of bottom definition by the Coast Survey was in the 1840's. These samples were initially taken with a lead line with a depression at its end. The bottom samples adhered to the wax placed in this depression. Curiosity played a large role in early attempts at bottom sample capture. An early practical application of identified bottom was to post anchoring attributes. Over the years more sophisticated grabbers were developed to improve the quality of samples. Parallel to the evolution of bottom sample, there has also been a gradual development in what makes the best source. 


\section{S-57 in CARIS HOB File}

Since 2000, captured bottom samples have been documented and retained in each hydrographic survey's digital hydrographic data feature file using International Hydrographic Organization special Publication 57 ("S 57) attribution in a CARIS Hydrographic Object ("HOB") file. This is the best source of bottom sample data. However, emerging methodology to extract bottom sample data from the processed data has not yet been perfected. The current CARIS processed survey data stream attribute delimitation is not uniform, requiring that the CARIS file format be reorganized to allow uniform bottom sample parsing. The text below in Fig. 1 depicts how the data is currently embedded in each surveys data stream. The inability to input this text information into the NGDC geospatial bottom sample data base is being addressed.

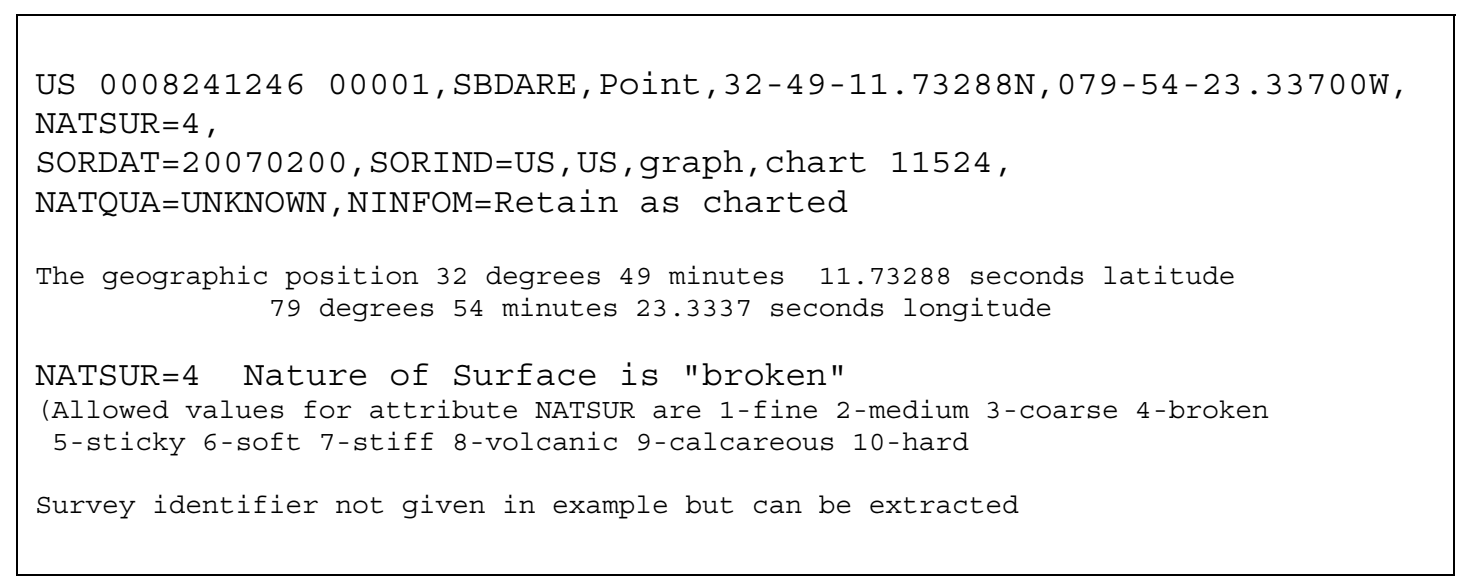

Fig. 1 SAMPLE DATA STREAM AND LOOKUP TABLE IN CARIS HOB.FILE

\section{"M" Log Sheets}

Bottom sample for surveys conducted between 1962 and 2000 were recorded manually on NOAA Form 75-44, commonly referred to as an "M" Log. A portion of an "M" log shown in Fig. 2 is an example of the second best source with latitude and longitude, sediment color, source vessel, project number and date. Although discontinued for many years, M" Logs still provide the authoritative bottom sample information for thousands of hydrographic surveys. This audit utilizes the NGDC map service Rap Sheet's two tiered bottom sample portrayal a portion of which is shown in Fig. 3 on the middle right. Clicking at the top of the box provides a link to the NGDC geographic position and type display showing the five bottom samples. The count and source from the NOS descriptive report are shown below the link. The display, also referred to as cruise samples, was transcribed by Smithsonian personnel from "M" log data sent by NOS. The work described here focused on using the "M" Logs to resolve as many mismatches in display and count as possible. Preliminary inspection of a recently discovered the National Geophysical Data Center Marine Geology Inventory has identified additional "M" Log entries for NOS hydrographic surveys that are not contained in the Smithsonian cruise data.

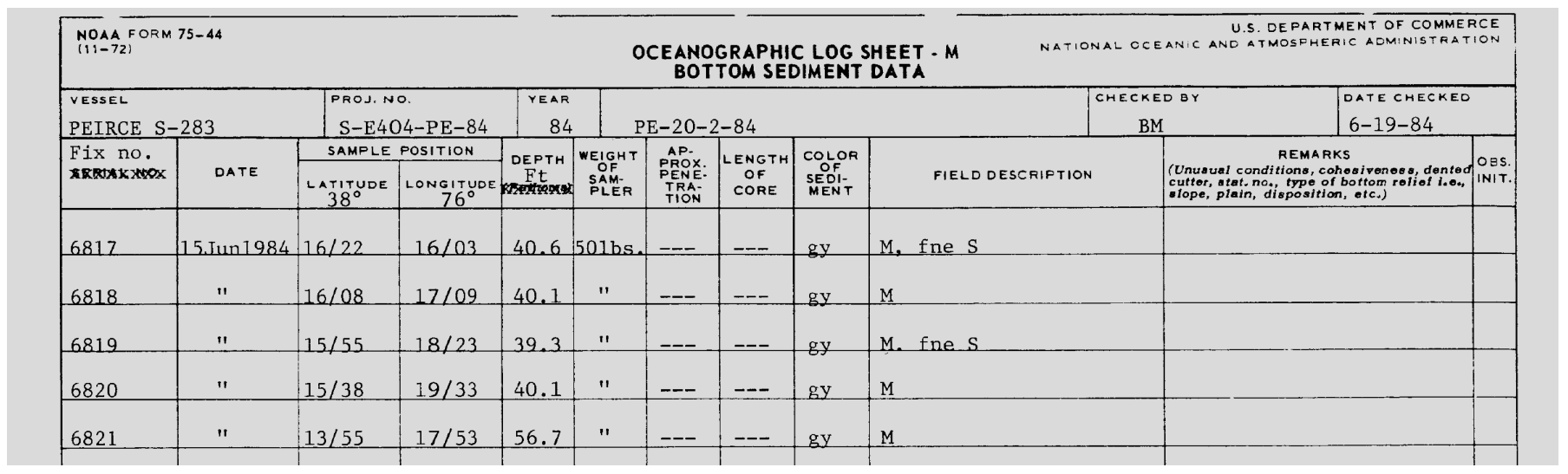

Fig. 2 PORTION OF SAMPLE "M" LOG 


\section{HydRographic SuRvey H09429 RAP SHEet}

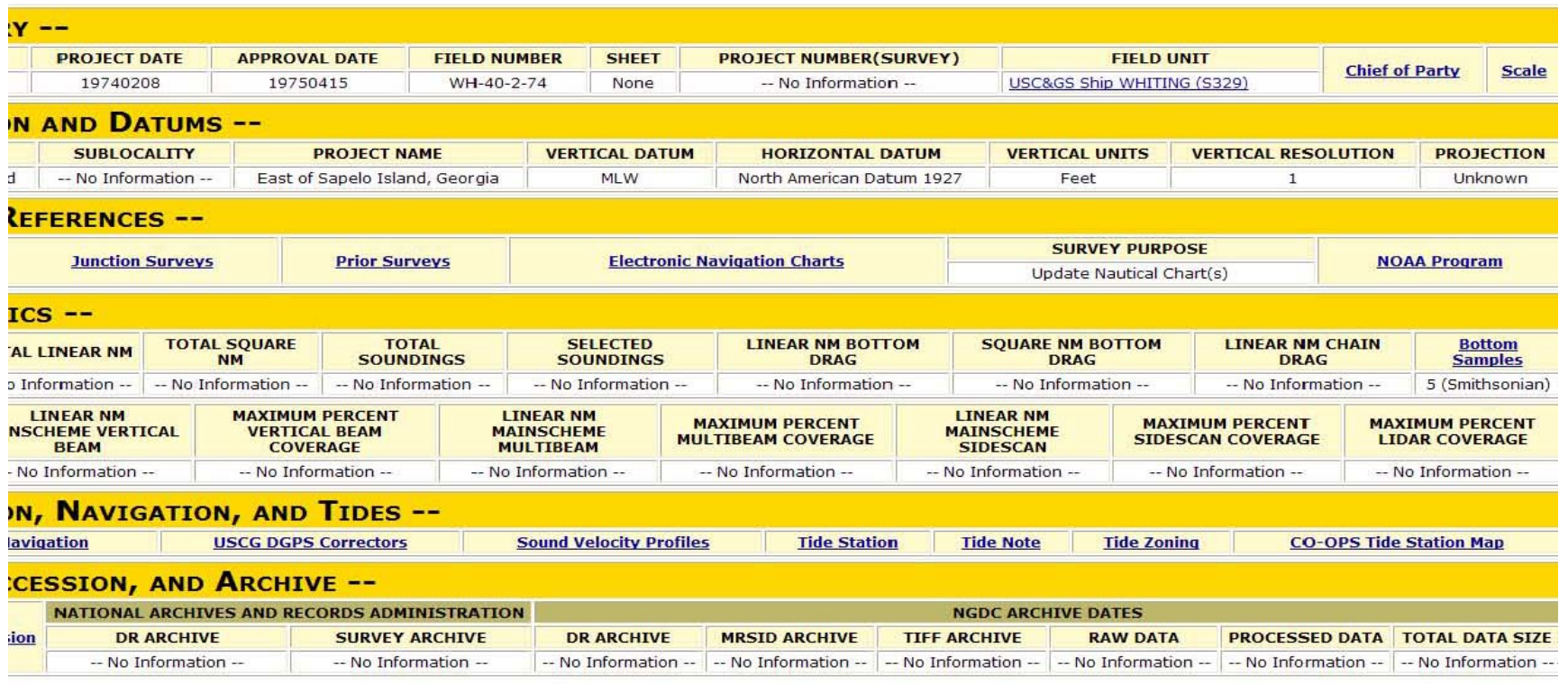

\begin{tabular}{|c|l|l|l|l|l|l|}
\hline Survey & \multicolumn{1}{|c|}{ Sample } & \multicolumn{1}{|c|}{ Latitude } & \multicolumn{1}{c|}{ Longitude } & \multicolumn{1}{c|}{ Description } & Source & $\begin{array}{c}\text { orig. } \\
\text { datum }\end{array}$ \\
\hline H09429 & SD00008039.01 & 31.38667 & -81.07333 & SAND FINE BROWN,SHELL BROKEN & NMNH & unkn \\
\hline H09429 & SD00008040.01 & 31.475 & -80.905 & SAND FINE GRAY,SHELLS BROKEN & NMNH & Unkn \\
\hline H09429 & SD00008041.01 & 31.57667 & -80.98333 & SAND FINE GRAY,SHELLS BROKEN & NMNH & unkn \\
\hline H09429 & SD00008042.01 & 31.58667 & -80.79333 & SAND FINE GRAY,SHELLS & NMNH & unkn \\
\hline H09429 & SD00009754.01 & 31.38667 & -80.79 & SAND COARSE BROWN,SHELLS & NMNH & unkn \\
\hline
\end{tabular}

Fig. 3 PORTION OF RAP SHEET BOTTOM SAMPLE COUNT/SOURCE (Middle Right) AND CRUISE DISPLAY BELOW

NOAA Hydrographic Survey Descriptive Reports

The third best source, the descriptive report tabular form shown in Fig. 4, provides a portion of bottom sample table form a descriptive report. This table has fewer bottom sample data attributes than the "M" Log. However, in all three of the bottom sample sources discussed thus far some general information can be obtained from the survey.

\begin{tabular}{|c|c|c|c|}
\hline \multicolumn{2}{|c|}{ CHART POSITION } & \multirow{2}{*}{$\begin{array}{c}\text { DELETE CHARTED } \\
\text { BOTTOM TYPE }\end{array}$} & \multirow{2}{*}{$\begin{array}{c}\text { CHART } \\
\text { BOTTOM TYPE }\end{array}$} \\
\hline LATITUDE & LONGITUDE & & \\
\hline $17^{*} 57^{\prime} 48^{\prime \prime} \mathrm{N}$ & $066^{\circ} 38^{\prime} 01^{\prime \prime} \mathrm{W}$ & $\mathrm{h}$ & M \\
\hline $17^{*} 57^{\prime} 38^{\prime \prime} \mathrm{N}$ & $066^{\circ} 38^{\prime} 21^{\prime \prime} \mathrm{W}$ & $\mathrm{rky}^{3}$ & $\mathrm{M}^{2}$ \\
\hline $17^{\prime} 57^{\prime} 07^{\prime \prime} \mathrm{N}$ & $066^{\circ} 38^{\prime} 17^{\prime \prime} \mathrm{W}$ & $\mathrm{h}$ & M \\
\hline $17^{\circ} 57^{\prime} 06^{\prime \prime} \mathrm{N}$ & $066^{\circ} 38^{\prime} 30^{\prime \prime} \mathrm{W}$ & rky & Sh, G \\
\hline $17^{*} 58^{\prime} 41^{\prime \prime} \mathrm{N}$ & $066^{\circ} 38^{\prime} 17^{\prime \prime} \mathrm{W}$ & $\mathrm{h}$ & $\mathrm{M}$ \\
\hline $17^{*} 58^{\prime} 18^{\prime \prime} \mathrm{N}$ & $066^{\prime} 38^{\prime} 13^{\prime \prime} \mathrm{W}$ & $\mathrm{h}$ & $\mathrm{M}$ \\
\hline
\end{tabular}

Fig. 4 PORTION OF SURVEY BOTTOM SAMPLE TABLE 
Charted Seabed Types

Working straight from the chart is the fourth method of recovering bottom sample data. In these charted bottom samples, the original source is not identified and the geographic positions must be scaled. Nonetheless, when a hydrographic survey has collected no bottom samples, a comment in the Rap Sheet top tier bottom sample links states that "charted bottom samples are the only source available.

\section{AUDIT METHODOLOGY AND TOOLS}

Prioritization of the four types of bottom sample source plays a critical role in the development of rules to resolve conflict between cruise display and descriptive report count. The following seven prioritized audit rules were developed during the cruise display and descriptive report audit. Table I outlines these rules which correct discrepancies, incorporate prioritized source and insure that all of the Rap Sheet survey displays have some bottom sample reference.

TABLE I BOTTOM SAMPLE DE-CONFLICTING RULES

\begin{tabular}{|c|l|}
\hline Rule & \multicolumn{1}{c|}{ Methodology } \\
\hline 1 & $\begin{array}{l}\text { For all entries, when available the PYDRO or Notebook feature file bottom samples } \\
\text { supersede all other conflicting source. }\end{array}$ \\
\hline 2 & $\begin{array}{l}\text { For all display entries, discovery and use of the original "M" log data supersedes the } \\
\text { conflicting cruise display. }\end{array}$ \\
\hline 3 & $\begin{array}{l}\text { For minor differences of up to three samples, the cruise display count and source will } \\
\text { override the bottom sample count. }\end{array}$ \\
\hline 4 & $\begin{array}{l}\text { For significant differences over three samples, NGDC data supersedes the HSMDB } \\
\text { bottom sample count and source when all display geographic positions fall within the } \\
\text { survey limits and the report accession archive sources offers no alternative record } \\
\text { corroboration. All data out of survey limits were deleted. }\end{array}$ \\
\hline 5 & $\begin{array}{l}\text { For surveys with a combination of Smithsonian and NOS samples, the cruise display } \\
\text { count and source supersedes the descriptive report count and source if the count } \\
\text { discrepancy of either source is less than 4. }\end{array}$ \\
\hline 6 & $\begin{array}{l}\text { For NGDC entries based on field number or project number, the NGDC display and } \\
\text { source will be relabeled with the survey number when positive matches are made to } \\
\text { HSMDB survey geographic coordinates, title sheet data and archive records. }\end{array}$ \\
\hline 7 & $\begin{array}{l}\text { For all survey entries with a count entry of "Not Collected for This Survey", the } \\
\text { display will be revised to reflect the charted samples. }\end{array}$ \\
\hline
\end{tabular}

These seven rules will be supplemented by a geographic position comparison routine in development which would compare cruise bottom sample geographic positions to the hydrographic survey outline. This would allow deletion of samples existing outside the survey area. The NGDC Map Service search engine identifies survey candidates matching known HSMDB attributes. Use of the search engine and the geographic position comparison routine together may provide a survey identifier for the 237 HSMDB entries transcribed with a Project Number identifier by Smithsonian personnel. Moreover, use of this methodology can discover additional survey bottom sample data from other databases such as the National Geophysical Data Center Marine Geology Inventory. It is very likely that this inventory has bottom sample data for many of the HSMDB surveys whose descriptive reports omit sample reference or mention some sampling was done with no follow up information.

\section{RESULTS}

Much progress has been made in satisfying the scope and objective of the project described in this paper. Verification of the NGDC Server HYDRO.DR_BOTTOM_SAMPLE table bottom sample source identification is now 100\% complete. This shows data for HSMDB bottom sample entries for NOAA hydrographic surveys H08000 to the present, F00200 to the present as well as all of the $\mathrm{D}$ and $\mathrm{W}$ surveys. Bottom sample content and source identification for the unknown category in Table II below still remains to be done. The bottom sample audit is now $80 \%$ complete. Resolving Smithsonian and NOS bottom sample counts 
found during the audit is $42 \%$ complete. Of the 4,436 total verified HSMDB entries there are $59 \mathrm{D}$ (Reconnaissance) 3,869 $\mathrm{H}$ (Hydrographic Surveys) 346 F (Field Edits) and $221 \mathrm{~W}$ (NOS/NAVOCEO/UHAWAII joint effort). The audit rules have resolved 213 conflicts. There are 287 conflicts remaining.

TABLE II TABULAR JULY 2010 BOTTOM SAMPLE AUDIT STATUS

\begin{tabular}{|l|c|}
\hline Category ( In Prioritized Order and Verification Status When Applicable) & Surveys \\
\hline NOS S57 (Verified PYDRO or Notebook Feature File) & 52 \\
\hline Smithsonian (Verified Transcribed Data Base) & 1,160 \\
\hline Combo (Smithsonian and NOS ) & 41 \\
\hline NOS ( Verified Samples Not Sent To Smithsonian) & 877 \\
\hline NOS Charted Bottom Samples & 88 \\
\hline NOS Bottom Samples Not Collected & 844 \\
\hline Unknown (Unverified Bottom Sample Data) & 1,374 \\
\hline Total (Verified and Unverified HSMDB Survey Entries) & 4,436 \\
\hline
\end{tabular}

\section{CONCLUSION}

Work still remains to complete the bottom sample geographic coordinate survey outline comparison routine and the user advisory to use charted bottom samples for all surveys were bottom samples were not collected. The author is also looking for other verifiable survey bottom sample sources. Plans are being made to enter these and any other data into an Excel spreadsheet that will be uploaded into the geospatial table at NGDC for future digitization

The target date for completion of the verified portion of the HSMDB is the end of the 2010. Plans are to extend the HSMDB bottom sample data by going further back. The H06000 series and H07000 series surveys as well as F00001 to F00200 Field Edits will be visited in 2011. Plans are also being made to expand current tracking of on-line HSMDB requests to include bottom samples and the users making the request. This will gage if mapping and modeling support of benthic habitat, and pollution, sediment transportation studies and coastal zone management is being successful. 